https://doi.org/10.15407/ujpe64.3.266

\title{
TO THE CENTENARY OF THE BIRTHDAY OF THE OUTSTANDING PHYSICIST I.Z. FISHER
}

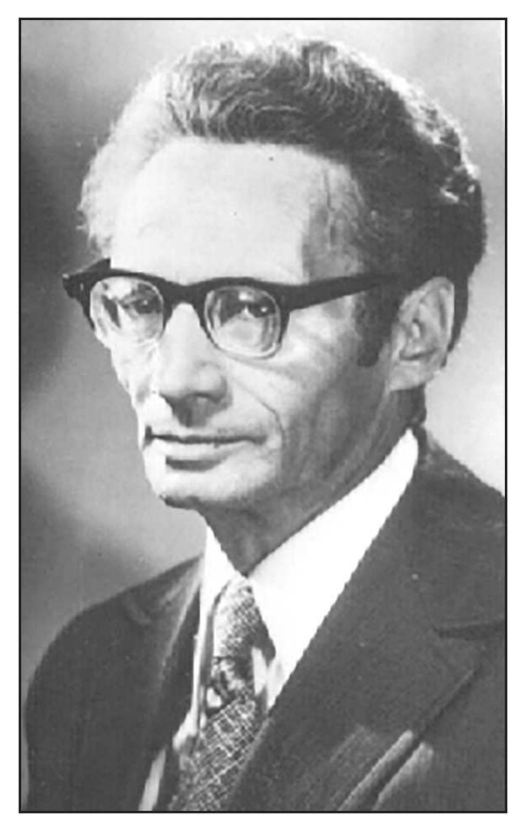

February 24, 2019 marks the 100th anniversary of the birth of the prominent physicist-theorist Iosif Zalmanovich Fisher, Professor of I.I. Mechnikov University of Odessa. He was born in Minsk. The young guy became fully aware of the horror of Stalin's repressions. At the end of 1937, his father was executed by shooting. The same year, his mother was sentenced to a prison term of seven years. In 1941, on the eve of the war, he graduated with distinction from the Faculty of Physics and Mathematics of the Belarusian State University (BSU).

Because of his extremely high short-sightedness, Iosif Zalmanovich was not recruited to the Red Army. In summer 1941, he worked as an assistant combiner; and, since autumn, as a teacher in the Stalingrad region. In 1942, the requirements to soldiers' health were softened, and Iosif Zalmanovich volun- teered to the front. He was a radio operator in a reconnaissance platoon of a separate howitzer regiment and remained in the active army till the end of the war. During reconnaissance operations, he drew fire many times. I.Z. Fisher was awarded an Order of the Red Star and Orders of the Patriotic War of the first and second classes, as well as a medal "For Bravery". The latter, since its initiation, was awarded exclusively for the personal courage shown in the battle and was highly respected among the front-line soldiers.

During the whole war, Iosif Zalmanovich carried "The Principles of Quantum Mechanics" by Dirac in his backpack and spent every silent minute to read it. His brother-soldiers recalled that he regularly exchanged 100 grams of alcohol given to every soldier before an attack (a Narkom dose) for rustic tobacco. They also recalled that, after every battle, all soldiers were looking for any glasses among the trophies for him. Iosif Zalmanovich was demobilized in October 1945.

The same year, I.Z. Fisher was hired as an assistant at the Chair of Theoretical Physics of the BSU. In 1947-1948, for one and a half years, he was a graduate student of M.S. Akulov. The Ph.D. thesis of Iosif Zalmanovich dealt with the role of gravitational forces in the meson interactions. This topic was chosen by the postgraduate student himself, on the basis of his speculations at the front. The results obtained in that dissertation retained their significance till now and have a high citation index. After defending the thesis, I.Z. Fisher returned to the Chair of Theoretical Physics at the BSU and had been working as an assistant professor for 12 years.

When being a postgraduate student, I.Z. Fisher got acquainted with the book of the famous Soviet mathematician and physicist N.N. Bogolyubov "Problems of

ISSN 2071-0194. Ukr. J. Phys. 2019. Vol. 64, No. 3 
Dynamic Theory in Statistical Physics". Almost immediately, he understood that the correlation functions are a very suitable tool for studying the properties of fluids and liquid metals. His hard work in this direction resulted in the defense of his doctoral dissertation in 1959. Two years later, the publishing house "Nauka", which was the most authoritative one in the Soviet Union, published I.Z. Fisher's monograph "Statistical Theory of Fluids". It was one of the first books in the world on this topic.

In 1962, the Rector of the Odessa State University (OSU) Oleksandr Ivanovych Yurzhenko invited I.Z. Fisher to the OSU and proposed him to head the Chair of Theoretical Physics. I.Z. Fisher accepted this proposal and, in 1963, moved to Odessa.

The authority of I.Z. Fisher as one of the greatest expert in the fluid physics domain grew permanently. The subject of his scientific researches included almost all challenging issues of liquid physics in the second half of the 20th century, as well as some problems in the gravitation theory. The most significant contribution was made by I.Z. Fisher to the development of the following scientific domains:

- the statistical theory of the properties of ordinary fluids;

- the theory of critical phenomena in fluids and solutions;

- the study of anomalous properties of water and liquid helium with impurities;

- the theory of collective transport in fluids;

- the theory of molecular light scattering in fluids and gases;

- the theory of systems with the Coulomb interaction between particles (plasma, liquid metals and semiconductors);

- the study of gravitational effects in the scalar field theory and in the Born-Infeld field theory, as well as the construction of macroscopic equations for the gravitational field.

The well-known Australian scientist C. Croxton gave the following estimate for I.Z. Fisher's scientific contribution: "Within last two or three decades, the fluid state physics, which invokes a growing interest, has reached considerable progress, generally speaking, owing to the pioneer works of Soviet authors; mainly, these are N.N. Bogolyubov, Ya.I. Frenkel, and I.Z. Fisher". According to L.D. Landau's statement, I.Z. Fisher's works favored the transformation of the physics of fluids from a "buckwheat por- ridge" into a rigorous branch of physical science. The most important achievement of I.Z. Fisher is the formulation of the theoretical basis for the collective transport in fluids. Later, the results obtained by Iosif Zalmanovich were experimentally confirmed by L.A. Bulavin in his works dealing with the thermal neutron scattering in fluids. In a definite sense, the significance of the results obtained in Fisher's works is comparable with that of the works associated with the Mössbauer effect. Without exaggeration, they can be classified to the most profound results obtained in the physics of fluids.

During 32 years of his scientific activity, I.Z. Fisher published about 140 works. He was extremely demanding with respect to the scientific level and style of the researches carried out by him and his collaborators. The linguistic perfection of his works deserves to be particularly mentioned. The main results of I.Z. Fisher were published in Zhurnal Eksperimentalnoi i Teoreticheskoi Fiziki, Doklady Akademii Nauk SSSR, Zhurnal Tekhnicheskoi Fiziki (about 50 papers), as well as other journals of the Academy of Sciences of the USSR. Four reviews were published in Uspekhi Fizicheskikh Nauk. The collaboration of Prof. I.Z. Fischer with Ukrainskyi Fizychnyi Zhurnal was also very close (about 20 papers). He regularly traveled to Moscow and made reports at specialized workshops. This form of account was also mandatory for most of his postgraduate students after a certain stage of their scientific training had been completed.

Professor I.Z. Fisher was a supervisor of 23 Ph.D. theses: 7 theses were defended at the BSU, and 16 theses at the OSU. Of those $23 \mathrm{PhDs}, 10$ scientists defended their doctoral dissertations later. The Chair of Theoretical Physics headed by I.Z. Fisher became one of the leading scientific centers of the USSR. Nowadays, it continues to maintain the world level of scientific researches. About 600 students graduated from the Faculty of Physics of the OSU in the specialty "theoretical physics" within 55 years since this specialty was re-initiated by I.Z. Fisher. More than 200 of them defended the Ph.D. theses, and more than 75 Dr.Sci. theses were defended as well. The graduates from the Chair now work at the universities in the USA, Germany, Israel, Great Britain, Canada, and other countries. This level of student training was undoubtedly one of the best in the USSR.

Every Wednesday, a seminar was held at the Chair of Theoretical Physics (CTP) of the Odessa Uni- 
versity. This seminar attracted attention of leading experts in the physics of fluids from the whole Soviet Union. On the basis of the sportive-recreative camp "Chornomorka", the CTP regularly held summer schools with the participation of scientists from the Landau Institute of Theoretical Physics, the Physical Institute of the Academy of Sciences of the USSR, the Institute of Physics of the Academy of Sciences of the UkrSSR, and other institutions. From year to year, the Nobel Prize laureates and Academicians A.A. Abrikosov and V.L. Ginzburg, Academician Ya.B. Zeldovich (the three times Hero of the Socialist Labor of the USSR), Academicians O.F. Andreev, L.V. Keldysh, A.B. Migdal, I.M. Khalatnikov, Professors V.L. Pokrovskii, O.Z. Patashinskii, Yu.I. Shimanskii, and others reported and lectured at the seminars held at the CTP and the Faculty of Physics of the OSU.

The outstanding achievements of I.Z. Fisher were honored in two special issues of the Journal of Molecular Liquids. For the first time, it was in 1993, when Iosif Zalmanovich was still alive, in connection with the 75th anniversary of his birthday. Next time, it happened in 2001, in commemoration of his 80th birthday. In this regard, the International Conference "Special Problems in Physics of Fluids" was orga- nized at the Odessa University in May 1999. On May 29, 2018, the All-Russian Seminar "Physics of Water and Aqueous Solutions" (chaired by M.M. Rodnikova) dedicated to the centenary of the birth of I.Z. Fisher was held in Moscow. In October 2018, a memorial plaque was installed on the facade of the Odessa National University, which was devoted to the fruitful work of I.Z. Fisher at this university. A seminar dedicated to I.Z. Fisher was held on December 20, 2018 at the Taras Shevchenko National University of Kyiv, where especially close relations were established under the supervision of Iosif Zalmanovych between the Chair of Molecular Physics of the Kyiv National University and the Chair of Theoretical Physics of the Odessa National University.

The creative life of I.Z. Fisher was interrupted by his serious illness in 1978. He died on May 25, 1995.

V.M. ADAMYAN, O.D. ALEKHIN, M.O. ANISIMOV, J. BARTHEL, L.A. BULAVIN, V.YA. GOTSULSKIY,

M.P. KOVALENKO, I.M. KOVAL', YU.P. KRASNYJ, V.E. KRUGLOV, M.I. LEBOVKA, S. MAGAZU, G. MAISANO, V.O. MAZUR, G.G. MALENKOV, M.P. MALOMUZH, G.E. NORMAN, M.M. RODNIKOVA, V.M. SYSOEV, A.I. FISENKO, B.A. VEYTSMAN 